Recebido: $17 / 09 / 2021$

Publicado: $28 / 12 / 2021$

\title{
REFLEXOS DA VULNERABILIDADE SOCIAL COMO PRESSUPOSTO PARA A ENTRADA DE ADOLESCENTES NA CRIMINALIDADE
}

\author{
Alda Penha Andrello Lopesi @0000-0001-5500-2896 \\ Centro Universitário UniFatecie \\ Magno Eugenio Marcelo Benomino da Silvaii $\oplus 0000-0002-7069-5122$ \\ Centro Universitário UniFatecie
}

RESUMO: As condições vulneráveis da sociedade vêm transferindo ao adolescente aspectos lesivos que necessitam de atenção. Dessa forma, o presente trabalho trata-se de revisão narrativa com o objetivo de conhecer e analisar o que a literatura especializada em psicologia e saúde, nos últimos 10 anos, traz a respeito dos reflexos da vulnerabilidade social como pressuposto para a entrada dos adolescentes na criminalidade. Foram exploradas as conceituações de vulnerabilidade social e adolescência, bem como a de criminalidade atualmente. Da mesma forma, abordou-se os diversos fatores que mais contribuem para que os adolescentes vulneráveis adentrem na seara criminosa em território brasileiro. Com isso, a busca dos artigos foi realizada nas plataformas
Scientific Eletronic Library (SciELO) e Periódicos Eletrônicos em Psicologia (PePSIC). Apenas 19 artigos enquadraram-se nos critérios de inclusão para este trabalho e 8 deles compuseram os resultados principais desta revisão. Apesar de haver uma escassez de artigos encontrados sobre o tema abordado, não permitindo grande aprofundamento, as publicações evidenciam a direta ligação das circunstâncias vulneráveis da sociedade com a inserção dos adolescentes ao submundo do crime nessa fase de constante dinamicidade psíquica e biológica, sendo as políticas públicas ainda ineficazes para a promoção de uma vida distante desses menores da prática de atos infracionais.

PALAVRAS-CHAVE: Vulnerabilidade social. Adolescentes. Criminalidade.

\section{REFLECTIONS ABOUT SOCIAL VULNERABILITY AS A GATEWAY FOR ADOLESCENTS TO ENTER INTO THE LIFE OF CRIMES}

\begin{abstract}
The vulnerable conditions of society have transmitted harmful aspects onto adolescents that we need to bring to attention. Thus, this paper uses narrative reviews with the objective of extracting information and analyzing the specialized psychology and health literature of the last 10 years that talk about the affects of social vulnerability on the adolescents and how it could lead them into a life of crime. Concepts like social vulnerability, adolescence as well as current criminality were researched. Also the various factors that most contribute to vulnerable adolescents entering the criminal arena were looked into in Brazilian territory. Thus, a search for articles was done on the Scientific Electronic Library (SciELO) and Electronic Journals in Psychology (PePSIC) platforms. Only 19 articles met the inclusion criteria for this paper and 8 of
\end{abstract}

them composed the main results of this review. Although there is a scarcity of articles found on the topic, not allowing for great depth, the publications show a direct connection of the vulnerable circumstances of society with the insertion of adolescents into the criminal underworld alongside the constant psychic and biological dynamism that occurs in this process. Making public policies that try to prevent this chain of events from happening ineffective in getting theses minor away from the practice of petty crime.

KEYWORDS: Social vulnerability. Adolescence. Criminal life. 


\section{Introdução}

A transição da infância para a vida adulta gera transformações inéditas ao indivíduo em aspectos biológicos, sociais e mentais. A adolescência é uma fase de grandes revoluções subjetivas, onde as influências da coletividade, bem como das tecnologias e do capitalismo, invocam novos comportamentos ao sujeito (MOREIRA et al., 2020).

A partir desse estágio de oscilações, se vislumbra muitas vezes, uma vinculação da vulnerabilidade advinda de questões sociais com os adolescentes, de forma cada vez maior com o passar dos anos. Tais condições vulneráveis são vistas como ricochetes de perigo pertinentes às situações frágeis dos ambientes em que esses jovens vivem, assim como da ausência de políticas públicas efetivas e estimulantes para estes (NEGREIROS et al., 2018).

A vivência de novas experiências que a referida fase da vida traz, são passíveis de comportamentos arriscados diante da curiosidade desenvolvida, associada às influências generalizadas do mundo e, atualmente, da mídia (PAULINO; LOPES, 2010).

A vulnerabilidade social abarca múltiplos aspectos que trazem a incapacidade de fomentar a cooperação do jovem em comunidade. Segundo Scott et al. (2018), este fenômeno não engloba apenas aspectos de pobreza, estando interligados fatores como renda, família, educação, saúde, entre outros.

No Brasil, os direitos absolutos impostos no ECA (Estatuto da Criança e do Adolescente), são constantemente violados, favorecendo a desigualdade e o descrédito destes menores (LUCENA, 2016). Todo esse contexto interfere na mente dos adolescentes, os quais estão passando por mutações que enlaçam diretamente as questões coletivas.

Com o aumento da criminalidade também na adolescência, verificando-se que a idade de entrada na criminalidade tem sido cada vez mais precoce, esta pesquisa justifica-se pela urgência da compreensão dos fatores que favorecem o envolvimento do adolescente com o crime para possíveis providências preventivas que modifiquem este caminho destrutivo que é percorrido quando um adolescente adentra à criminalidade. Estas medidas podem ser tanto no âmbito das políticas públicas estatais como familiares e de orientação e formação em que o profissional da psicologia poderá ser um dos envolvidos neste trabalho multiprofissional.

A fim de melhor compreender o tema, a pesquisa foi realizada com base em artigos científicos, sendo o presente trabalho estruturado em tópicos e subtópicos com o objetivo de analisar e evidenciar as vertentes da literatura na área da Psicologia, sobre os aspectos do envolvimento dos adolescentes brasileiros do início do século XXI com a criminalidade sob o enfoque dos reflexos advindos da vulnerabilidade social. 


\section{Desenvolvimento}

2.1 Considerações a respeito da vulnerabilidade social e da adolescência

A conceituação de vulnerabilidade social é perceptivelmente complexa, não possuindo uma definição uníssona, sendo caracterizada na maioria da literatura da Psicologia como evento associado as condições de vida dos indivíduos. É um termo utilizado a fim de representar os grupos minoritários, atrelados a elementos lesivos, os quais são resultados negativos de comportamentos tanto estatais quanto sociais (MORAIS; RAFFAELLI; KOLLER, 2012).

É uma consequência de procedimentos sociais que conferem à assistência deficiente, precária e desigual à população (MORAIS; KOLLER; RAFFAELLI, 2010). E diante disso, é possível aferir que a vulnerabilidade social pertence ao cenário socioeconômico das comunidades e o alcance de oportunidades para seu desenvolvimento (SCOTT et al., 2018). A partir dessa, a mente humana é largamente impactada diante das circunstâncias expostas (SOUZA; PANUNCIO-PINTO; FIORATI, 2019).

Esse fenômeno em constante crescimento, desencadeia o amedrontamento do futuro, afastando as pessoas de sua essência e princípios, tornando-as incrédulas na sociedade (XAVIER; CHAGAS; REIS, 2019). Negreiros et al (2018), condiciona a vulnerabilidade com risco, onde circunstâncias morais, sociais, financeiras e psicológicas são afetadas. Os mesmos autores aduzem que o local em que o adolescente vive e sua comodidade podem se tornar meios dificultosos para seu caminho até a maturidade.

A adolescência, por sua vez, trata-se de fase da vida com uma grande colisão comportamental, na qual os indivíduos vão tecendo seus hábitos e decisões, se deparando com contínuas mudanças e experimentando novas atitudes. É um momento de busca por sua real identidade, marcado por instabilidade emocional (BITTENCOURT; FRANÇA; GOLDIM, 2015).

Com efeito, pode-se dizer que é produto da Modernidade, ciclo diversificado e subjetivo onde os indivíduos são chamados a solucionar premissas pelas quais na infância não tinham consciência de tal. E, com o aumento da perspectiva de vida e das tecnologias, é possível verificar uma certa dificuldade de estabelecer o momento da transição da infância, adolescência e vida adulta (LIMA et al., 2019). 
O Estatuto da Criança e do Adolescente, considera adolescente a pessoa com idade entre doze e dezoito anos (BRASIL, 1990). A referida lei foi pensada a fim de proteger integralmente as crianças e adolescentes do país com políticas públicas sociais dignas e garantidoras dos direitos desses (FONSECA et al., 2013).

Já a Organização Mundial de Saúde, define a adolescência como a fase compreendida entre os dez e dezenove anos completos (OMS, 2016). E nesse âmbito, a lei caracteriza os direitos deste como absolutos, devendo ser protegidos pelo Estado, família e sociedade, oferecendo sempre uma vida digna aos menores (CHECA et al., 2018).

\section{$2.2 \mathrm{O}$ adolescente vulnerável e a criminalidade}

O adolescente vulnerável é aquele que sofre limitações culturais e coletivas, vítimas da fragilidade familiar, escolar e do Estado (OLIVEIRA et al., 2020). A existência dos fatores de risco sociais, as condições emocionais em indefinição e a busca pelo encaixe em determinado grupo levam à vulnerabilidade do adolescente podendo contribuir para a entrada no submundo do crime, ao uso de drogas e bebidas alcoólicas (FONSECA et al., 2013).

Fonseca et al. (2013), aduzem que o estado de vulnerabilidade do adolescente, o sujeita à uma vida submissa e indefesa perante ao meio social e o Estado. Em consequência disso, sofre abalos em sua saúde mental e física, principalmente daqueles com condições financeiras desfavoráveis.

No Brasil, a desigualdade diante do mau funcionamento do Estado leva aos fatores de risco sociais que se tornam desafios para a sobrevivência desses pré-adultos. Aliado a isso, as vulnerabilidades dos adolescentes brasileiros decorrem dos vícios dos pais, das violências familiares, da falta de estrutura educacional do país e, muitas vezes, da precariedade do local de moradia que por consequência traz as formas de exploração infantil (FONSECA et al., 2013).

A criminalidade atualmente, segundo Xavier, Chagas e Reis (2019), é um dos resultados do capitalismo o qual conduz à uma sensação de satisfatoriedade àqueles em situação de vida degradante. Esse fenômeno provém também das desigualdades que afetam, em sua maioria, os mais vulneráveis socialmente.

Conforme Oliveira et al. (2019), a criminalidade se torna mais assídua diante da ruptura ou fragilidade dos elos sociais. Trata-se, portanto, de evento afrontoso à coletividade que precisa ser reestabelecida, sendo o praticante do ato delituoso punido com sanções impostas por 
lei (LIMA et al., 2019). E o que se constata atualmente é o potencial avanço da criminalidade ante o aumento exponencial do capitalismo (LUCENA, 2016).

Correlacionando o adolescente com a criminalidade, Lima et al. (2019, p. 373), leciona:

Temos, portanto, anexado à noção de criminalidade, não apenas uma vertente eminentemente sociológica, mas também um aspecto subjetivo importante, uma vez que o crime parece apresentar uma solução singular ao jovem que se vê interpelado pela puberdade e que encontra na atividade ilícita uma saída para o impasse adolescente.

Dessa forma, o adolescente vulnerável vislumbra o "mundo do crime" como porta de saída das circunstâncias externas e internas. No entanto, ao praticar os atos delituosos, este sofrerá sanções impostas pelo Estado, por meio do ECA, chamadas de medidas socioeducativas. Tais medidas tentam disciplinar o menor a arcar com suas responsabilidades e resgatar seu estado inicial, fora das infrações (SOUZA; MOREIRA, 2017).

2.3 Motivos ensejadores da entrada do adolescente vulnerável na criminalidade e aspectos psicológicos

O âmbito familiar e escolar, muitas vezes, não exerce seu papel de acolhimento e propensão para uma vida estruturada aos menores (BITTENCOURT; FRANÇA; GOLDIM, 2015). As intercorrências violentas executadas pelo Estado, família e o meio social geral, exemplificadas pela exploração, maus tratos e abandono sem tratamentos adequados, assombram os jovens que a partir dessas se inserem em uma vida de transgressão (LUCENA, 2016).

Impende destacar que a ausência de recursos financeiros também é um dos elos para a entrada do adolescente na criminalidade, concomitantemente com o setor precário de educação e saúde (RAUTER; MAIA, 2016). Conforme Xavier, Chagas e Reis (2019), a escassez hodierna diante do desemprego, interfere diretamente no crescimento das ações delituosas.

Nessa mesma vertente, o mercado de consumo também tem servido como atrativo para a introdução dos menores no meio infracional. Isto porque, a alienação gera o consumismo generalizado e a busca pela satisfação na ostentação de objetos, suprime, muitas vezes, o desequilíbrio das relações sociais (LUCENA, 2016).

Assim, diante da fase em que o adolescente vive e perante a sociedade capitalista e consumerista, não mede esforços e, tampouco sopesa as consequências dos atos que serão 
praticados para conquistar os produtos almejados, apenas interessa-se em tê-los, independente de possuir ou não condições financeiras de o adquirir licitamente (LUCENA, 2016).

O uso de entorpecentes também é uma das causas para o ingresso do adolescente no mundo ilusório do crime. A dependência química faz com que o jovem se aliene e ignore espontaneamente a legislação pátria para que seu vício seja mantido. Ele se vê diante da facilidade do cometimento de infrações para conquistar o que deseja, resultando na falsa sensação de felicidade (CHECA et al., 2018).

Conforme Oliveira et al. (2020), o vício em drogas ilícitas intensifica a vulnerabilidade dos adolescentes, afetando sua saúde física e mental além de contribuir para os colapsos escolares, familiares e para a delinquência.

As infrações penais se apresentam ao adolescente vulnerável como solução de problemas, um local falsamente seguro para fugir das confusões mentais que o atormentam nesse momento de transição. Dessa forma, é cada vez mais complexo precisar a interferência social e a mutação psicológica nessa etapa da vida (LIMA et al., 2019).

É visível que a situação vulnerável dos adolescentes emerge em todas as circunstâncias que o cercam e principalmente em seu desenvolvimento psicológico e emocional (SOUZA; PANUNCIO-PINTO; FIORATI, 2019). O luto pela transição da infância para a fase pré-adulta, as transformações do corpo com uma exacerbada baixa autoestima, os questionamentos sobre a vida e o futuro, tal como o anseio pela aceitação coletiva favorecem a alternativa da criminalidade (GUERRA et al., 2010).

Segundo Oliveira et al. (2019), a formação da mente do adolescente vulnerável que ingressa na criminalidade é assinalada principalmente pela debilidade no seio familiar. Além disso, a fragilidade do vínculo escolar e a falta de políticas estatais assíduas, interferem na mente do menor que busca no crime o conforto e um espaço de reconhecimento. Desse modo, as faltas, rupturas e ilusões ensejam a busca pelos atos infracionais.

\section{Materiais e Métodos}

Para realização deste estudo percorreu-se as plataformas de dados PePSIC e Scientific Eletronic Library Online (SciELO), estabelecendo como buscadores os termos "vulnerabilidade social", "adolescentes", "psicologia", "crime" e "criminalidade".

Nas referidas bases, foram considerados materiais de natureza multivariada, compondose por artigos científicos que examinam de forma ampla o tema abordado. Após, foi realizada 
a leitura e fichamento dos artigos estudados, a fim de envolver apenas aqueles diretamente condizentes com a questão explorada.

Este artigo tem como natureza narrativa/descritiva e procedimento de cunho bibliográfico e documental, com abordagem qualitativa. O objetivo é demonstrar e problematizar o nexo entre a vulnerabilidade social com a entrada dos adolescentes na criminalidade atualmente.

Nesse sentido, a revisão narrativa consiste em forma de estudo expansiva, a qual permite o estabelecimento de associação com materiais múltiplos sobre o tema escolhido, a fim de obter uma melhor compreensão e soluções pertinentes atuais (ROTHER, 2007).

Segundo Silva (2010), a abordagem qualitativa conduz a um desempenho amplo, admitindo um aprofundamento contextual harmonizado com a ilustração da realidade e dos comportamentos.

Para inclusão, foram selecionados artigos publicados no período de dez anos (2010 a 2020), no idioma português, disponíveis on-line em textos completos de livre acesso. Os critérios de exclusão foram publicações duplicadas nas plataformas e com baixa conexão ao objetivo do presente artigo.

\section{Resultados e Discussões}

Diante da escassez de material sobre o tema abordado, a busca nas bases de dados teve de ser refinada e detalhada para oferecer respostas atuais ao tema escolhido. Inicialmente, resultou-se em 107 artigos (SciELO: 93 e PePSIC: 14) com os termos "vulnerabilidade social" e "adolescentes". Com a pesquisa dos vocábulos "adolescentes" e "crime", proveio o total de 57 referências (SciELO: 30 e PePSIC: 27). Dos descritores "criminalidade" e "psicologia", resultaram 22 artigos (SciELO: 15 e PePSIC: 7). A expressão "criminalidade" juntamente com “adolescentes", obtiveram-se a somatória de 23 materiais (SciELO: 8 e PePSIC: 15).

Realizada a triagem, foram excluídos 190 artigos duplicados ou com temáticas com baixa conexão com o tema abordado. Após a leitura na íntegra dos 19 artigos selecionados, 11 foram tratados na fundamentação teórica, uma vez que se tratava de aspectos mais conceituais ou distintos do objetivo fim da revisão. Assim, apenas 8 artigos corresponderam ao intuito central desse estudo para composição dos principais resultados desse trabalho, conforme ilustrado na figura a seguir. 
Figura - Fluxograma da escolha dos artigos.

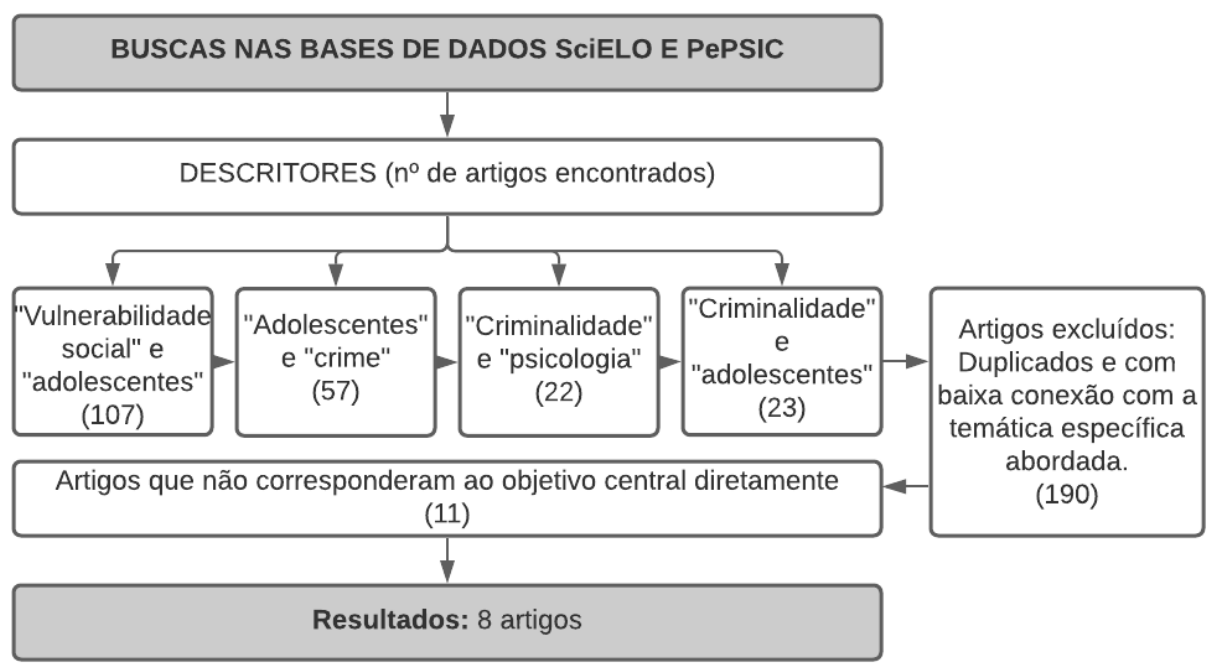

Fonte: autoria própria.

Para melhor compreensão, realizou-se um detalhamento conforme a tabela abaixo que organiza os artigos encontrados, ano de publicação, objetivos e os descritores utilizados para a pesquisa.

Tabela - Caracterização das publicações/ano de publicação e descritores pesquisados.

\begin{tabular}{|c|c|c|}
\hline ARTIGO/ANO & OBJETIVOS & DESCRITORES \\
\hline $\begin{array}{l}\text { 1. Construindo ideias sobre a } \\
\text { juventude envolvida com a } \\
\text { criminalidade violenta. - } \\
2010 \text {. }\end{array}$ & $\begin{array}{l}\text { Levantamento de hipóteses } \\
\text { sobre a relação do jovem com } \\
\text { a criminalidade pelo } \\
\text { enlaçamento social. }\end{array}$ & $\begin{array}{l}\text { "Criminalidade" } \\
\text { "psicologia". }\end{array}$ \\
\hline $\begin{array}{l}\text { 2. Adolescentes em situação } \\
\text { de vulnerabilidade social e o } \\
\text { continuum risco-proteção. - } \\
\text { 2012. }\end{array}$ & $\begin{array}{l}\text { Identificação da forma como } \\
\text { os fatores de } \\
\text { vulnerabilidade }\end{array}$ & $\begin{array}{l}\text { "Vulnerabilidade social" e } \\
\text { "adolescentes". }\end{array}$ \\
\hline $\begin{array}{l}\text { 3. As vulnerabilidades na } \\
\text { infância e adolescência e as } \\
\text { políticas públicas brasileiras } \\
\text { de intervenção. - } 2013 \text {. }\end{array}$ & $\begin{array}{l}\text { Discussão sobre as } \\
\text { vulnerabilidades na infância e } \\
\text { adolescência bem como a } \\
\text { análise das políticas públicas } \\
\text { interventivas. }\end{array}$ & $\begin{array}{l}\text { "Vulnerabilidade social" e } \\
\text { "adolescentes". }\end{array}$ \\
\hline
\end{tabular}




\begin{tabular}{|c|c|c|}
\hline $\begin{array}{l}\text { 4. A vulnerabilidade e a } \\
\text { mente: conflitos simbólicos } \\
\text { entre o diagnóstico } \\
\text { institucional e a perspectiva } \\
\text { de jovens em cumprimento de } \\
\text { medida socioeducativa. - } \\
\text { 2014. }\end{array}$ & $\begin{array}{l}\text { Discussão sobre a noção de } \\
\text { vulnerabilidade diante do } \\
\text { sistema socioeducativo e dos } \\
\text { aspectos psicológicos. }\end{array}$ & $\begin{array}{l}\text { "Vulnerabilidade social" e } \\
\text { "adolescentes". }\end{array}$ \\
\hline $\begin{array}{l}\text { 5. O fenômeno da ideologia } \\
\text { e a criminalidade infanto- } \\
\text { juvenil. }-2016 \text {. }\end{array}$ & $\begin{array}{l}\text { Debate das concepções } \\
\text { ideológicas sobre a juventude } \\
\text { e a entrada na criminalidade } \\
\text { precocemente. }\end{array}$ & "Crime" e "adolescentes". \\
\hline $\begin{array}{l}\text { 6. Adolescentes autores de } \\
\text { atos infracionais e o } \\
\text { sentimento de culpa. - } 2017 \text {. }\end{array}$ & $\begin{array}{l}\text { Compreensão do } \\
\text { envolvimento do adolescente } \\
\text { com } \\
\text { criminalidade/transgressão da } \\
\text { lei e o sentimento de culpa. }\end{array}$ & "Crime" e "adolescentes". \\
\hline $\begin{array}{l}\text { 7. Curso de vida, } \\
\text { adolescentes e criminalidade: } \\
\text { uma leitura a partir do PIA. - } \\
2019 .\end{array}$ & $\begin{array}{l}\text { Exposição do percorrer } \\
\text { infracional dos adolescentes e } \\
\text { sobre a capacidade do sistema } \\
\text { socioeducativo de reinserção } \\
\text { na coletividade. }\end{array}$ & $\begin{array}{l}\text { "Criminalidade" } \\
\text { "psicologia". }\end{array}$ \\
\hline $\begin{array}{l}\text { 8. "Sobrevivendo": } \\
\text { vulnerabilidade social } \\
\text { vivenciada por adolescentes } \\
\text { em uma periferia urbana. - } \\
2020 \text {. }\end{array}$ & $\begin{array}{l}\text { Compreensão dos principais } \\
\text { fenômenos que cercam os } \\
\text { adolescentes e os colocam em } \\
\text { vulnerabilidade social. }\end{array}$ & $\begin{array}{l}\text { "Vulnerabilidade social" e } \\
\text { "adolescentes". }\end{array}$ \\
\hline
\end{tabular}

Fonte: autoria própria.

Tomando como parâmetro os artigos analisados, percebe-se que o direcionamento que vem sendo tomado é de que as condições vulneráveis sociais estão diretamente relacionadas com a adolescência, violando suas garantias fundamentais previstas na legislação pátria.

A vulnerabilidade social, geralmente, traz uma condição traumática ao adolescente, refletindo em suas reações e hábitos. Esse contexto vulnerável leva-os à prática de atos infracionais além disso, os fatores biológicos remetem à uma fase indefesa, intensificada pelos coeficientes sociais (MALVASI; ADORNO, 2014). 
Os adolescentes são ludibriados com a facilidade proveniente do crime, atendendo aos seus desejos e sua imagem de sujeito de direitos perante a comunidade (LUCENA, 2016). Essa busca pela inserção na coletividade, diante das várias limitações do cenário social, se mostra como uma escora ante ao seu sentimento de desproteção (OLIVEIRA et. al., 2020).

Guerra et al. (2010), aponta uma "carência estrutural" na vida desses menores, bem como um processo de luto na transição da adolescência para a idade adulta. Muitos passam a vida sem uma estrutura familiar linear, com a ausência das figuras masculinas e femininas de referência ou são deixados de lado pelas ocupações diárias dos pais. Ainda, são desprovidos de laços sociais e culturais.

Da mesma forma, o capitalismo exacerbado influencia e oferece objetos de desejo consignados nas tecnologias, fazendo com que esses futuros adultos projetem a falha simbólica da família e da sociedade para a vida no crime. Ou seja, buscam na criminalidade a satisfação plena diante das faltas vivenciadas nessa etapa de vida em questão (GUERRA et al., 2010).

Para Oliveira et al. (2019), o percurso dos adolescentes no crime é reflexo da vulnerabilidade social associada com as dificuldades de relação interpessoal com a família e as instituições de ensino, o que culmina na evasão escolar e leva estes aos vícios e as práticas dos atos infracionais. Ademais, o déficit de políticas estatais, da mesma forma que a ineficácia do Sistema Socioeducativo limita a possibilidade de uma vida de sucesso ao jovem.

Em seus estudos, Morais et al. (2012), obteve mediante entrevistas com adolescentes de distintas bases (familiares e de rua), que nem sempre aquele que é vulnerável socialmente apresenta progresso negativo, de forma a entrar na criminalidade ou no vício do uso de entorpecentes. Ou seja, é preciso analisar pormenorizadamente cada caso e sua relação com os indivíduos ao redor destes, assim como com os eventos estressores envolvidos que podem ser, muitas vezes, os causadores do vínculo delitivo.

Nesse aspecto, a debilidade com a instituição familiar e escolar, bem como o desejo pelo ajustamento em um grupo, associam-se à fatores de risco. Por outro lado, ressalta-se a importância das mencionadas entidades, já que são nesses ambientes que o adolescente desenvolve e estrutura sua identidade, cria uma saúde psicológica, do mesmo modo que se sente protegido na maioria dos casos (MORAIS et al., 2012).

Oliveira et al. (2020), levanta que apesar das entidades educacionais possuírem um valor grandioso para o adolescente, os preconceitos e agressões vividos em tal universo também o colocam em uma posição de violência, naturalizando-a. Igualmente, o uso de substâncias psicoativas que traz sentimentos de prazer e superação de opressões, é porta de entrada para a 
criminalidade crescente entre os menores, bem como para o avanço da situação vulnerável à coletividade.

Fonseca et al. (2013), coloca a integração das políticas públicas estatais, no que diz respeito aos problemas referentes à inserção dos adolescentes no crime, como evolutivas. No entanto, propõe uma maior efetivação para que os direitos estabelecidos no ECA sejam integralizados.

Em divergência, Lucena (2016), afirma que há uma ilusão da população decorrida do Estado de que as medidas socioeducativas atuais moderam a criminalização das crianças e adolescentes. O autor se contrapõe às políticas públicas administradas para o tratamento dos menores infratores, sendo estas mesmas violadoras de direitos. Afirma que as ações estatais reprimem e conduzem ao retrocesso da nova geração ao invés de reverter a situação de criminalidade nesse trajeto.

Para a superação da reprodução das condições vulneráveis socialmente no crime, Oliveira et al. (2020), diante de seus estudos, conferiu este poder à família, ao esporte e às atividades laborais. Esses meios são vistos como sinônimo de mudança e restauração. No entanto, os autores relatam que as intervenções estatais ainda são ineficazes para o tratamento dos adolescentes que se desenvolvem em estado de vulnerabilidade.

Souza e Moreira (2017, p. 84), trazem a psicanálise como intervenção contributiva para compreensão dos atos dos adolescentes vulneráveis infratores:

Pode-se dizer que, a partir da contribuição da Psicanálise, faz-se imprescindível considerar o sujeito do inconsciente, a dimensão singular do ato infrator, para que os laços sociais possam ser reestabelecidos por esses adolescentes, cada qual a seu modo e tempo.

As autoras retratam a entrevista com um menor em cumprimento de medida socioeducativa a associação da solução fácil e rápida pela qual os delitos oferecem e o extravio do mesmo de sua família. Por meio da terapia, o adolescente foi compreendendo e refletindo sobre a responsabilidade a si atribuída por meio da medida estatal imposta. A restrição de sua liberdade o aproximou dos seus ascendentes e o desconforto geral causado pelo cometimento dos atos infracionais passou a ser constante (SOUZA; MOREIRA, 2017).

As medidas socioeducativas implementadas pelo Estado conjuntamente com o apoio psicológico tentam edificar o que estava destruído na mente e no corpo do adolescente. E dessa forma, deve o poder público intervir de forma positiva a fim de que possibilite a renovação da vida desses menores marginalizados (SOUZA; MOREIRA, 2017). 


\section{Considerações Finais}

Com base nesse estudo, é possível verificar que o tema abordado, os reflexos da vulnerabilidade social como pressuposto da entrada dos adolescentes no crime, é ainda escasso na literatura da área da Psicologia.

Diante dos resultados, a vulnerabilidade social de fato traz reflexos ao desenvolvimento psicológico do adolescente brasileiro neste início de século, acrescido da fragilidade afetiva e econômica, bem como as consequências do uso de entorpecentes e bebidas alcoólicas. Sua capacidade de ressocialização e reabilitação, infelizmente, resta questionada diante de seu desenvolvimento psíquico que ainda se encontra em fase de amadurecimento.

Necessita-se, portanto, de um tratamento com maior efetivação de proteção dos adolescentes. A influência familiar e anímica positiva, bem como a participação e comprometimento nas atividades escolares, esportivas e laborais, são fatores perspicazes para a proteção dos adolescentes e a redução da probabilidade de condutas transgressoras desses.

Além disso, a interferência do Estado com imposição de políticas públicas preventivas e eficazes deve ser fortalecida. Embora o ECA tenha por objetivo garantir direitos aos adolescentes, alguns dos autores pesquisados, entre eles, Fonseca et al. (2013), afirmam que ainda são necessários muitos avanços para o cumprimento deste Estatuto, constatando que em muitas situações os direitos previstos pela referida norma estão longe de ser garantidos. $\mathrm{O}$ investimento na saúde e educação dos jovens, tal como na área de segurança pública é primordial.

O envolvimento do adolescente com a criminalidade deve ser tratado com extrema cautela, uma vez que a delinquência nessa fase frágil da vida acarreta inseguranças pessoais, psíquicas e jurídicas. Assim, a condição da vulnerabilidade advinda de questões sociais deve atualmente ser utilizada como caminho de proteção daqueles atingidos fortemente por esta.

Em conclusão, é importante que haja a constante pesquisa envolvendo as situações de vulnerabilidade social e os adolescentes diante da dinamicidade das gerações, das tecnologias e do mundo em geral que contemplam imensas mudanças na psicologia.

\section{REFERÊNCIAS:}

BITTENCOURT, Ana Luiza Portela; FRANCA, Lucas Garcia; GOLDIM, José Roberto. Adolescência vulnerável: fatores biopsicossociais relacionados ao uso de drogas. Revista Bioética, Brasília, v. 23, n. 2, pág. 311-319, 2015. Disponível em: https://doi.org/10.1590/1983-80422015232070. Acesso em: 05 mai. 2021. 
BRASIL. Planalto. Lei no 8.069 de 13 de julho de 1990. Diário Oficial da União, Brasília, 1990. Disponível em: http://www.planalto.gov.br/ccivil_03/leis/18069.htm. Acesso em: 05 mai. 2021.

CHECA, Maria Eduarda Parizan et al. Desobediência, Alargamento da Punição e Segurança Pública: Jovens Usuários de Drogas em Conflito com a Lei. Psicologia: Ciência e Profissão, Brasília, v. 38, n. spe2, p. 252-264, 2018. Disponível em: https://doi.org/10.1590/19823703000212842. Acesso em: 01 mai. 2021.

FONSECA, Franciele Fagundes et al. As vulnerabilidades na infância e adolescência e as políticas públicas brasileiras de intervenção. Revista Paulista de Pediatria, São Paulo, v. 31, n. 2, p. 258-264, 2013. Disponível em: http://dx.doi.org/10.1590/S0103-05822013000200019. Acesso em: 18 mai. 2021.

GUERRA, Andréa Máris Campos et al. Construindo ideias sobre a juventude envolvida com a criminalidade violenta. Estudos e Pesquisas em Psicologia, Rio de Janeiro, v. 10, n. 2, p. 434456, 2010. Disponível em: http://pepsic.bvsalud.org/scielo.php?script=sci_arttext\&pid=S180842812010000200010\&lng=pt\&nrm=iso. Acesso em: 14 mai. 2021.

LIMA, Rodrigo Goes et al. Trajetórias e narrativas de adolescentes envolvidos com a criminalidade: os objetos e suas formas de aproximação em transdisciplinaridade. Psicologia em revista, Belo Horizonte. v. 25, n. 1, p. 365-380, 2019. Disponível em: http://dx.doi.org/10.5752/P.1678-9563.2019v25n1p365-380. Acesso em: 08 mai. 2021.

LUCENA, Cledina Dantas. O fenômeno da ideologia e a criminalidade infanto-juvenil. Revista Katálysis, Florianópolis, v. 19 n. 1, p. 73-80, 2016. Disponível em: https://doi.org/10.1590/1414-49802016.00100008. Acesso em: 01 mai. 2021.

MALVASI, Paulo Artur; ADORNO, Rubens de Camargo Ferreira. A vulnerabilidade e a mente: conflitos simbólicos entre o diagnóstico institucional e a perspectiva de jovens em cumprimento de medida socioeducativa. Saúde e Sociedade, São Paulo, v. 23, n. 1, p. 30-41, 2014. Disponível em: https://doi.org/10.1590/S0104-12902014000100002. Acesso em: 08 mai. 2021.

MORAIS, Normanda Araujo de; KOLLER, Sílvia Helena; RAFFAELLI, Marcela. Eventos Estressores e Indicadores de Ajustamento entre adolescentes em Situação de Vulnerabilidade Social no Brasil. Universitas Psychologica, Bogotá, v. 9, n. 3, p. 787-86, 2010. Disponível em: http://www.scielo.org.co/scielo.php?script=sci_arttext\&pid=S1657-

92672010000300015\&lang=pt. Acesso em: 10 mai. 2021.

MORAIS, Normanda Araujo de; RAFFAELLI, Marcela; KOLLER, Sílvia Helena. Adolescentes em situação de vulnerabilidade social e o continuum risco-proteção. Avances en Psicología Latinoamericana, Bogotá, v. 30, n. 1, p. 118-136, 2012. Disponível em: http://www.scielo.org.co/scielo.php?script=sci_arttext\&pid=S1794-

47242012000100010\&lng=en\&nrm=iso. Acesso em: 06 mai. 2021.

MOREIRA, Jacqueline de Oliveira et al. Ambivalência da escola e adolescentes infratores. Psicologia Escolar e Educacional, Belo Horizonte, v. 24, 2020. Disponível em: https://doi.org/10.1590/2175-35392020195027. Acesso em: 05 mai. 2021. 
NEGREIROS, Daniele Jesus et al. Risco e vulnerabilidade: pontos de convergência na produção brasileira sobre juventudes. Revista Desidades, Rio de Janeiro. n. 18, p. 20-33, 2018. Disponível em: http://pepsic.bvsalud.org/scielo.php?script=sci_arttext\&pid=S231892822018000100003\&lng=pt\&nrm=iso. Acesso em: 05 mai. 2021.

OLIVEIRA, Lucas Caetano Pereira et al. Curso de vida, adolescentes e criminalidade: uma leitura a partir do PIA. Psicologia e Sociedade. Belo Horizonte, v. 31, 2019. Disponível em: https://doi.org/10.1590/1807-0310/2019v31210441. Acesso em: 10 mai. 2021.

OLIVEIRA, Patrícia Carvalho de et al. "Sobrevivendo": vulnerabilidade social vivenciada por adolescentes em uma periferia urbana. Interface - Comunicação Saúde, Educação, Botucatu, v. 24, 2020. Disponível em: https://doi.org/10.1590/interface.190813. Acesso em: 18 mai. 2021.

ORGANIZAÇÃO MUNDIAL DA SAÚDE. Saúde mental dos adolescentes. Disponível em: https://www.paho.org/pt/topicos/saude-mental-dos-adolescentes. 2016. Acesso em: 05 mai. 2021.

PAULINO, Janaina Aparecida; LOPES, Renata Ferrarez Fernandes. Relação entre percepção e comportamento de risco e níveis de habilidades cognitivas em um grupo de adolescentes em situação de vulnerabilidade social. Psicologia: Ciência e Profissãa, Brasília. v. 30, n. 4, p. 752-765, 2010. Disponível em: https://doi.org/10.1590/S1414-98932010000400007. Acesso em: 03 mai. 2021.

RAUTER, Cristina; MAIA, Kenia Soares. A contestação adolescente e sua saúde: resistindo aos estigmas e aos processos de criminalização contemporâneos. Revista Epos, Rio de Janeiro, v. $7, \quad$ n. $1, \quad$ p. 56-73, 2016. Disponível em: http://pepsic.bvsalud.org/scielo.php?script=sci_arttext\&pid=S2178700X2016000100004\&lng=pt\&nrm=iso. Acesso em: 30 abr. 2021.

ROTHER, Edna Terezinha. Revisão Sistemática x Revisão Narrativa. Acta Paulista de Enfermagem, São Paulo, v. 20, n. 2, 2007. Disponível em: http://dx.doi.org/10.1590/S010321002007000200001. Acesso em: 23 abr. 2021. Editorial

SCOTT, Juliano Beck et al. O conceito de vulnerabilidade social no âmbito da psicologia no Brasil: uma revisão sistemática da literatura. Psicologia em Revista, Belo Horizonte, v. 24, n. 2, p. 600-615, 2018. Disponível em: http://dx.doi.org/10.5752/P.1678-9563.2018v24n2p600615. Acesso em: 01 mai. 2021.

SILVA, Gisele Cristina Resende Fernandes da. O método científico na psicologia: abordagem qualitativa e quantitativa. 2010. Disponível em https://www.psicologia.pt/artigos/textos/A0539.pdf. Acesso em: 24 abr. 2021.

SOUZA, Juliana Marcondes Pedrosa; MOREIRA, Jacqueline Oliveira. Adolescentes autores de atos infracionais e o sentimento de culpa. Revista Subjetividades, Fortaleza, v. 17, n. 3, p. 82-91, 2017. Disponível em: http://dx.doi.org/10.5020/23590777.rs.v17i3.5515. Acesso em: 19 mai. 2021.

SOUZA, Larissa Barros de; PANUNCIO-PINTO, Maria Paula; FIORATI, Regina Célia. Crianças e adolescentes em vulnerabilidade social: bem-estar, saúde mental e participação em 
educação. Cadernos Brasileiros de Terapia Ocupacional, São Carlos, v. 27, n. 2, p. 251-269, 2019. Disponível em: https://doi.org/10.4322/2526-8910.ctoao1812. Acesso em: 18 mai. 2021.

XAVIER, Antônio Roberto; CHAGAS, Eduardo Ferreira; REIS, Edilberto Cavalcante. Direito positivo, miséria social e violência no capitalismo globalizado. Serviço Social \& Sociedade, São Paulo, n. 134, p. 107-123, 2019. Disponível em: https://doi.org/10.1590/0101-6628.168. Acesso em: 19 mai. 2021.

\footnotetext{
i Mestre em Educação pela Universidade Estadual de Maringá (2012), Especialização em Psicanálise pela Universidade Estadual de Londrina (1995), Especialização em Terapia Cognitivo-Comportamental pela Veda (2017), Especialização em Administração e de Recursos Humanos pela Faculdade Estadual de Educação, Ciências e Letras de Paranavaí, (1991), Graduação em Psicologia pela Universidade Federal do Paraná (1980). Atualmente é professora titular do Centro universitário UniFatecie, coordenadora do curso de Psicologia do Centro universitário UniFatecie e atua como profissional autônomo na Psicoclínica. Email: alda.penha@ fatecie.edu.br ii Advogado e graduado no curso de Psicologia do Centro Universitário UniFatecie. Email: magnoeugenio.5203@fatecie.edu.br
} 